\section{SURGICAL AND \\ INTERVENTIONAL HYBRID \\ PROCEDURES: LESSONS FROM CHINA AND BEYOND}

To the Editor:

We read with great interest Hu's report $^{1}$ in the June issue of the Journal on the status of surgical and interventional cardiovascular hybrid procedures in China. The hybrid concept combines the treatments traditionally available only in the catheterization laboratory with those traditionally available only in the operating room to offer patients the best available combination of treatments for any given set of cardiovascular lesions. Since their introduction, these hybrid procedures have been increasing in China with the opening of more than 30 hybrid operating rooms.

We and others ${ }^{1,2}$ have advocated for a "one-stop" model of hybrid therapy. In such a multipurpose cardiovascular operating suite (the hybrid operating room), patients can undergo coronary artery bypass grafting followed immediately - within minutes, in the same operative setting-by percutaneous coronary intervention. Other applications include hybrid minimally invasive valve surgery and percutaneous coronary intervention, hybrid debranching aortic arch procedures, and hybrid endocardial and epicardial atrial fibrillation ablation. This onestop approach improves efficiency and reduces cost, and it may also help to reduce the risks associated with patient transfers and handoffs.

\footnotetext{
The Editor welcomes submissions for possible publication in the Letters to the Editor section that consis of commentary on an article published in the Journal or other relevant issues. Authors should: - Include no more than 500 words of text, three authors, and five references. - Type with double-spacing - See http://jtcs.ctsnetjournals.org/misc/ifora.shtm for detailed submission instructions. - Submit the letter electronically via jtcvs.editorialmanager.com. Letters commenting on an article published in the JTCVS will be considered if they are received within 6 weeks of the time the article was published Authors of the article being commented on will be given an opportunity of offer a timely response ( 2 weeks) to the letter. Authors of letters will be notified that the letter has been received. Unpublished letters cannot be returned.
}

The hybrid operating room is probably the best venue for transcatheter valve implantation. In the hybrid operating room, femoral or axillary cutdown and certainly direct aortic approach are not barriers whatsoever. A traditional catheterization laboratory is limited by the lack of surgical lights and sterile environment, whereas a traditional operating room is limited by inadequate imaging capacity. Furthermore, the staffs in the traditional environments rarely interact and rarely share skill sets. In the hybrid operating room, a new species of hybrid technologist has emerged. The hybrid technologist is able to assist the hybrid surgeon and interventionist in performing these integrated procedures.

Cardiac surgeons in China seem to have embraced training in catheterbased skills, with the introduction of a catheter-based training program 5 years ago. In North America, where only a few surgeons have made the leap to be trained also in catheterbased skills, a hybrid procedure typically requires a strict collaboration between the interventional cardiologist and the cardiac surgeon. Moreover, the current training system does not provide adequate training to our surgical residents in catheterbased skills. In our view, modern training programs in cardiac surgery and cardiology should limit traditional general surgery (and general medicine) training to perhaps 2 years and include more intense cardiovascular and catheter-based training. One of the major barriers to this idea is our current reimbursement system.

Many academic centers in the US are not organized as integrated delivery systems. The different specialists (surgeons, cardiologists, radiologists, anesthesiologists) typically reside in different departments, which are also separate from the hospitals. Patients thus often experience sequential visits to multiple providers, physicians, and departments, with multiple testing at times duplicate or redundant. In our view, US academic centers need to move toward integrated delivery systems that place patient needs at the center, resulting in much greater value for patients. ${ }^{3,4}$ In such a system, the compensation model will need to align everyone's interests around improving overall value for patients. ${ }^{3,4}$ As a consequence, the evaluation of outcomes should be performed not separately for each intervention (coronary artery bypass grafting, percutaneous coronary intervention) but over the full cycle of care for a medical condition.

The concept of a cardiovascular sciences department or service line, wherein all cardiovascular providers reside in a single cost center together with the hospital, is not new. Its implementation has been limited, however, because of traditional reimbursement and funding flow models. Although the hybrid operating room and hybrid procedures are important and certainly need to be in the armamentarium of the modern cardiovascular specialist, they are just the embodiment of an effective hybrid organization.

John G. Byrne, MD

Marzia Leacche, $M D$

David X. Zhao, MD

The Vanderbilt Heart \& Vascular Institute

Nashville, Tenn

\section{References}

1. Hu S. The surgical and interventional hybrid era: experiences from China. J Thorac Cardiovasc Surg. 2011;141:1339-41.

2. Zhao DX, Leacche M, Balaguer JM, Boudoulas KD, Damp JA, Greelish JP, et al. Routine intra-operative completion angiography after coronary artery bypass grafting and 1-stop hybrid revascularization results from a fully integrated hybrid catheterization laboratory/operating room. J Am Coll Cardiol. 2009;53:232-41.

3. Porter ME. A strategy for health care reform-toward a value-based system. $N$ Engl J Med. 2009; 361:109-12.

4. Porter ME, Teisberg EO. Redefining health care: creating value-based competition on results. Boston: Harvard Business School Press; 2006.

doi:10.1016/j.jtcvs.2011.09.047 